\title{
The history of cytomegalovirus and its diseases
}

\author{
Monto Ho
}

Received: 24 September 2007 / Published online: 18 December 2007

(c) Springer-Verlag 2007

\begin{abstract}
Intranuclear inclusions typical of cytomegalovirus infections were first noticed in 1881 by German scientists who thought they represented protozoa. After viruses were grown in cell cultures, Weller, Smith and Rowe independently isolated and grew CMV from man and mice in 1956-1957. Antibodies in 30-100\% of normal adults indicate not only a past infection, but the presence of a present latent infection. The presence of CMV DNA in tissues and most organs surveyed indicates the ubiquity of latent infection. CMV disease requires the virus and some deficiency of immunity such as occurs in the immature fetus, in AIDS, and in transplant patients on immunosuppressive drugs. Antiviral agents can inhibit CMV replication but they cannot prevent or cure latent infections. A pharmacological approach using the many leads in understanding latency is needed.
\end{abstract}

Keywords Antiviral therapy · CMV in AIDS - CMV after transplantation - Discovery of CMV $\cdot$ Epidemiology of CMV $\cdot$ Latent infection by CMV

\section{Discovery of cytomegalovirus}

Ribbert [1] wrote that in 1881, he saw large cells in sections of the kidney of a luetic stillborn and in the parotid gland of children which he was unable to interpret until he saw the report of Jesionek and Kiolemenoglou ([2], Fig. 1), who described similar cells as "protozoan like" cells in the lungs, kidneys and liver of an 8-month luetic fetus. The

M. Ho $(\square)$

618 Friendship Circle, Pittsburgh, PA 15241-3998, USA

e-mail: monto@pitt.edu; montoho@hotmail.com eccentrically placed nuclei of these large cells contained a "central nuclear body" surrounded by clear halo. Lòwenstein [3] working in Ribbert's laboratory found such cells in the parotid glands of 4 out of 30 infants. These appear to be the first descriptions of typical cytomegalic cells with intranuclear inclusions.

Von Glahn and Pappenheimer [4] noted that Lipschuetz [5] had discovered intranuclear inclusion containing cells in lesions in man infected by herpes zoster and herpes genitalis. Thus they believed such abnormal cells were produced by viruses, and they doubted that they were related to protozoa. This was the first indication that cells with intranuclear inclusions might be related to a group of related viruses, now known as the herpesviridae.

Farber and Wolbach [6] found such inclusion bearing cells in the salivary glands of 26 out of 183 children examined after death from diverse causes. This was the first approximation of the fact that infection by cytomegalovirus is highly frequent.

By 1932, 25 cases of a rare lethal congenial infection characterized by petechiae, hepatosplenomegaly, and intracerebral calcification had been described. All of them had cells with typical intranuclear inclusions. Wyatt et al. [7] suggested the name, "generalized cytomegalic inclusion disease (CID)", although its viral etiology was not yet known. A uniform site of involvement were cells of the renal tubules. They suggested that the disease might be diagnosed during life by searching for cells with inclusions in urinary sediments.

Following this clue, Fetterman [8] made a cytological preparation from the urine sediment of a suspected case, and made the first intravitum diagnosis of CID.

Minder [9] first saw by electronmicroscopy $199 \mathrm{~nm}$ particles, suggestive of a virus, in the clear halo around the intranuclear inclusion of pancreatic cells in a case of CID. 
Fig. 1 Left Cells with intranuclear inclusions with halo thought by Jesionek and Kiolemenoglou [2] to represent parasites. Right CMV infected cytomegalic cell with intranuclear inclusion with halo. Note also cytoplasmic inclusion on the left side of the cell
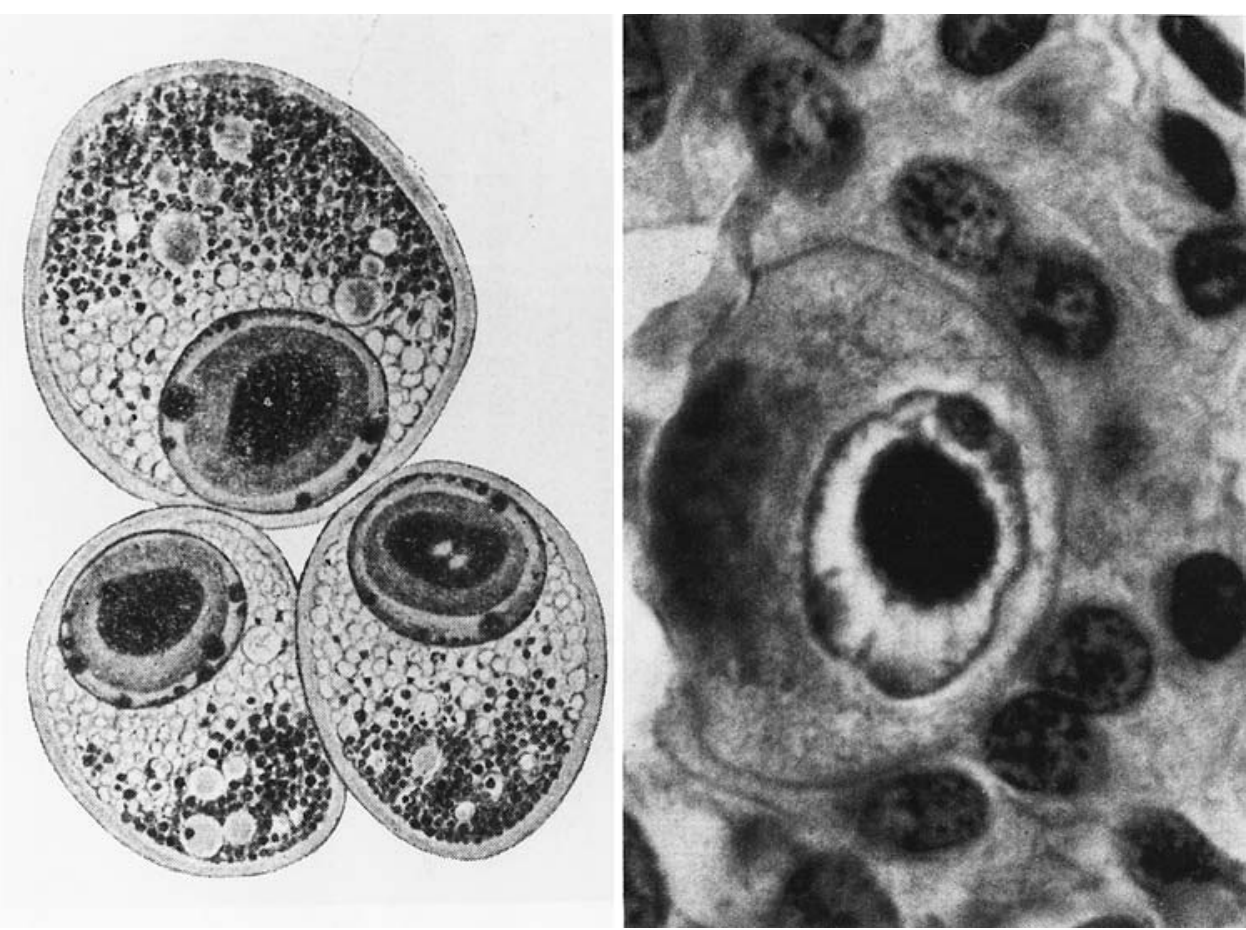

Human CMV could not be cultured until human cells were routinely grown in culture. This became possible after Enders et al. [10] isolated poliovirus in human embryonic cell cultures. They received the Nobel Prize in 1954 for this achievement. Enders' and Weller's laboratories at Harvard University became a Mecca for virologists throughout the world who were eager to learn this technique. Weller was a pediatrician and parasitologist. Applying the newly discovered cell culture techniques, he was initially interested in culturing the protozoa Toxoplasma in human embryonic culture. Toxoplasma gondii causes a lethal congenital disease in neonates remarkably similar to CID clinically. From an infant suspected to have congenital toxoplasmosis, a virus later identified as cytomegalovirus was isolated in 1957 ([11], Fig. 2).

Earlier, in 1955, Margaret Smith isolated from the salivary gland of a dead patient a virus which grew only in human but not in mouse cell culture. The paper describing this finding was rejected because she was also working with the mouse salivary gland virus and the editor thought her human agent might have been a mouse contaminant. We now know that this was not correct because cytomegaloviruses are specific in their respective animal species. It was only in 1956 when she reisolated the virus and isolated the same virus from the kidney of another patient with CID that her paper was accepted [12].

Rowe et al. [13], who were interested in respiratory viruses, isolated from adenoid tissue of a subject a virus that he suspected to be varicella virus, since it had cells with intranuclear inclusions like those described by Weller

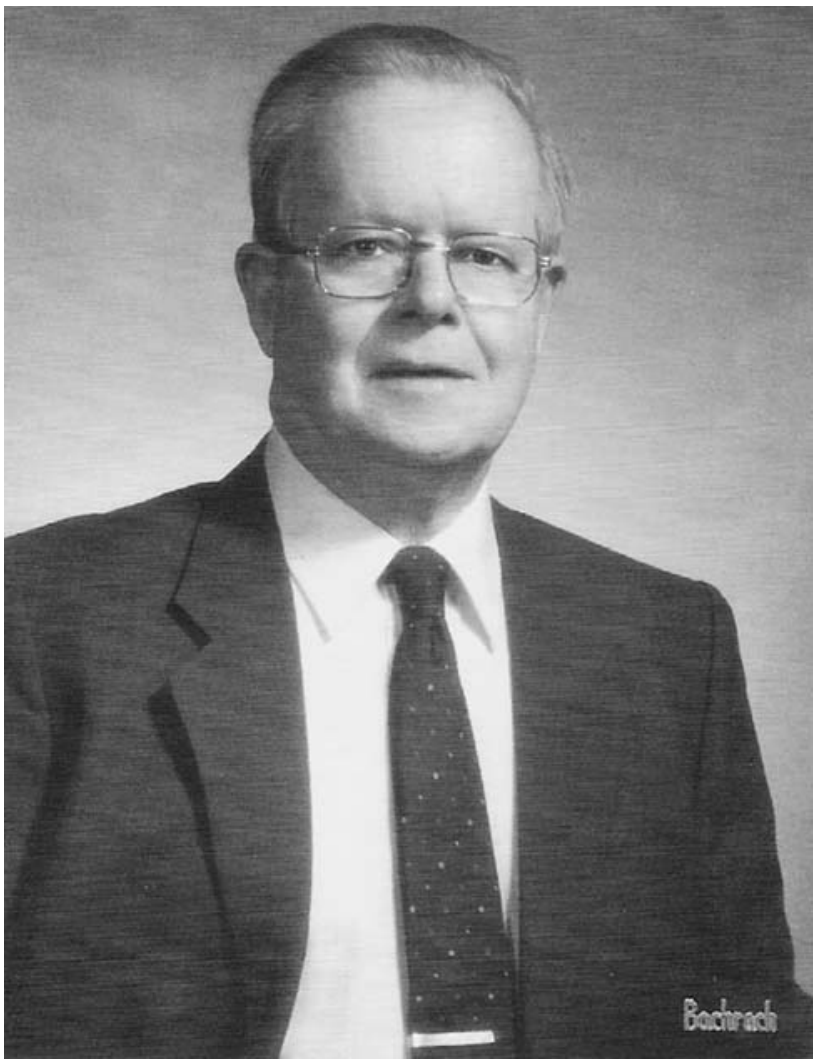

Fig. 2 Thomas H. Weller, pediatrician, parasitologist and virologist, discoverer of CMV, emeritus professor and chair, Department of Tropical Public Health, Harvard School of Public Health, Boston, MA

in 1953 in cases of varicella [14]. Rowe took his material to Weller's lab for confirmation. Weller determined that his virus was not varicella virus but that it was similar to the 
virus Weller had isolated from the patient with suspected toxoplasmosis [11].

These three independently isolated agents were exchanged among the three scientists, and the similarity of agents recovered was established in advance of publication [15]. This is an excellent and commendable example of collaboration in science! Weller named the virus "cytomegalovirus".

Weller et al. [16] tested serum from two cases of CID against 14 isolates using the complement-fixation (CF) test, including the 3 isolates mentioned above. The early 3 months serum acted in high titers against the homologous strains, but only in low titers against the heterologous strains. This was the first indication of strain differences among CMV isolates. More recently, Boppana et al. [17] studied maternal serum with preconceptual immunity against CMV before and after conception of an infant with congenital CMV infection; ten of the 16 mothers with congenitally infected children acquired new antibody specificities against glycoprotein $\mathrm{H}(\mathrm{gH})$. This protein is part of the armamentarium of neutralizing antibodies. The gene for $\mathrm{gH}$ is highly pleomorphic and is partially responsible for the heterogeneity of CMV isolates. This heterogeneity explains the phenomenon of superinfection of one strain upon another in a single patient. This finding also explains why immunity from infection is not absolute in CMV. It also creates a problem for the design of an effective vaccine [18]. Another source of strain variation is in vitro cultivation. Cha et al. [19] found that the Towne strain, which is a cell culture derived vaccine strain, lacked large segments of the genome found in recent clinical isolates not frequently passed in cell cultures.

\section{Scope of cytomegalovirus infection and disease}

The discovery of CMV in cell culture made it possible to identify and measure lytic virus in pathological materials infected by CMV using the morphological method of cytopathology.

An offshoot of the discovery of cytomegalovirus was the development of tools to study the epidemiology of past and latent infections of CMV. Rowe et al. [13] prepared a CMV antigen by sonic inactivation of the virus and used it to develop a complement fixation (CF) test. He used this test to measure the antibodies in the general population in Washington, DC [13]. The CF test became the mainstay method to study the epidemiology of CMV by measuring specific antibodies against CMV for 20 years. Later it would become apparent that the presence of circulating antibodies not only indicated past infection, but that it indicated the presence of latent infection by CMV, not apparent by cytopathology. Latent infection occurs pari passu with acquired immunity and is not cured by it. At times, silent latent infection may be activated so that lytic virus is produced. In the immunogically competent subject, virus shedding is usually asymptomatic, such as shedding of CMV in urine, in saliva, in the uterine cervix, in semen and in milk. In the presence of immune deficiency, activation of latent infection may result in a gamut of symptomatic clinical diseases (see below).

Rowe et al. [13] found that in Washington, DC, subjects over 35 years old were $81 \%$ seropositive. The frequency of seropositivity increased with age. This conclusion was generally confirmed by others in other population groups throughout the world [20].

There were however important differences in different population groups. Generally, there was an inverse correlation with socio-economic conditions, the lower strata having higher frequencies. This is the case within different nations, and also among different nations. Northern European nations, North America and Australia have lower rates (40-60\%) than nations in Southeastern Asia and Africa, where it is close to $100 \%$ [21].

Instead of being a rare infection as might be expected from the rarity of CID, CMV infection was found to be ubiquitous but usually asymptomatic. This was indicated by the high frequency of CMV specific antibodies in the general human population.

There are two age ranges during which there is a large amount of infection. The first is infection during the perinatal period (0-2 years). Infection during this period may be measured by seroconversion or by viruria. The sources of infection of these children are virus shed from the uterine cervix of the mother [21], virus in breast milk of the mother [22], and virus from saliva and urine [23]. CMV from the uterine cervix may infect the neonate during its passage through the birth canal. Breast milk may contain shed virus from a seropositive mother which may infect the nursing infant. There may be a community problem if breast milk is pooled as in some Scandinavian countries. CMV in urine and saliva from newly infected infants and toddlers may be the source of infections as fomites in nurseries, day care centers and large families. Perinatal infection with CMV indicated by the presence of viruria may reach as high as $56 \%$ in some studies [22].

Sexual transmission of CMV represents the second most important mode of horizontal transmission after puberty. CMV mononucleosis has been epidemiologically associated in partners of heterosexual sex [24, 25]. CMV shedding from the uterine cervix of females has been associated with number of sex partners, early age of first intercourse, and being nonwhite [26].

CMV infection is even more strongly associated with homosexual sex in the immunocompetent gay male. There is a vast difference between the frequency of seropositivity 
in the gay male compared with hetereosexual males of the same socio-economic stratum (94 vs 54\%, [27]). CMV seropositivity or latent infection was correlated with duration of sexual activity, number of sexual partners, history of syphilis and anal intercourse [28, 29]. Interestingly, there is also evidence of continuous lytic infection activity in the immunocompetent healthy sexually active gay male. This is indicated by the high titer and long duration of circulating CMV specific IgM antibodies; the high frequency of semen shedding of CMV (35\%, [30]), and the high frequency of urine shedding as detected by serial testing $(30 \%)$.

\section{Modes of infection: lytic and latent infection}

Despite the tremendous surge of knowledge of the molecular biology of cytomegalovirus and anti-CMV immunology, the understanding of the mechanisms of latent infections is still incomplete [31]. This includes the nature of the latent state, how it is maintained, and the processes of its activation to a lytic infection.

In 1975, we [32] did a study about CMV seroconversion after kidney transplantation. We found that 10 out of 12 (83\%) seronegative recipients who received an organ from a seropositive donor converted to seropositivity within three months after their operation. From this we deduced that the grafted kidney was the vehicle of transmission of $\mathrm{CMV}$, and that it harbored latent CMV infection. Later, we and others found that this was also the case with other types of organ transplantation, such as transplantations of the heart, liver and lung (for review, see [33]). For the first time we used seropositivity as a sign of latent CMV infection besides immunity against CMV. Although we could not find any virus upon culturing kidneys from seropositive subjects, we suspected that latent CMV infection without demonstrable production of lytic viruses exists probably in all organs of the body of seropositive subjects. After allograft transplantation of any organ, the latent CMV infections in the grafted organs are activated, and the recipient becomes infected or superinfected with intact, lytic virus, which stimulates the production of antibody. This hypothesis has now been confirmed by Hendrix et al. [34]. They found that CMV DNA, demonstrated by dot blot hybridization and in situ hybridization with a probe for immediate early (IE) sequences (UL123), and by nested PCR with primers derived from immediate early gene (UL123 exon 4), was found widely distributed in organs of healthy subjects, including the liver, kidney, spleen, pancreas and smooth muscle cells in arterial walls. Significantly, immunochemical studies using monoclonal antiserum against UL123 protein were negative, suggesting that the DNA positive sites represented sites of latent infection without IE gene expression or lytic intact virus.
A predominant current theory is that latent infection is harbored in undifferentiated monocytes, by which it is extensively distributed in various organs of the body [35]. Latency represents blockage of virus production at the level of expression of IE antigen. This blockage is released after differentiation of monocytes, or when latent infection can be activated to produce lytic virus infection.

\section{Determinants of diseases}

CMV disease is produced by the action of intact lytic virus and attendant pathological reactions, including inflammation. These produce clinical signs and symptoms which together constitute a syndrome called disease. Infection may occur de novo, as a primary infection, or it could arise secondarily in an immune patient; that is from reactivation of a latent infection already present in the patient or by reinfection with a new strain in the patient. Primary infection occurs in seronegative subjects without prior specific immunity against CMV. Secondary infection occurs in seropositive individuals who already have some specific immunity against CMV. Primary infection occurring in the absence of specific immunity produces a more severe disease than secondary infection. Primary infection as opposed to secondary infection is the first and most important determinant of CMV disease.

The second major determinant of CMV disease is immunological deficiency. As mentioned above, even most primary infections in humans are asymptomatic. No trace of the infection is observable except seroconversion. On top of immunological incompetence, however, disease has become more common. Much CMV disease has been brought about by modern medicine, specifically the wide spread use of immunosuppressants in oncology and transplantation medicine, and the prolonged survival of the very young. Specific immunosuppressants of cellular or $\mathrm{T}$ cell immunity are uniformly applied after major organ transplantation to maintain the integrity of the graft. Immunity against organ graft and immune defenses against CMV and other herpesviruses are not clearly distinguishable. Patients now survive with deficiencies in immunity that underlie CMV diseases, in many cases not yet clearly elucidated, such as deficiencies related to the unborn fetus (see below).

Perhaps the best example of immunological deficiency in determining CMV disease is an experiment of nature, the newly emergent disease, AIDS, or "acquired immunological deficiency syndrome". The deficiency is primarily that of cellular or T cell immunity. Immunological competence can be clinically quantified precisely by the peripheral blood $\mathrm{T}$ cell count, which normally is around $800 \mu \mathrm{L}^{-1}$. Symptomatic CMV disease, types often rarely found in man, occurs after the immunological state is severely 
compromised, or when the $\mathrm{T}$ cell count decreases to 100 $\mu \mathrm{L}^{-1}$ or lower.

In other cases, the nature of the immunological incompetence determining CMV disease is obscure or only unclearly understood. Extreme young age in humans is a critical determinant of CMV disease. An infant in utero is at great risk for developing CMV disease. The earliest recognized CMV disease was CID, which results from a primary infection of the mother during pregnancy, where the infant is infected congenitally through the placenta and primarily, in utero (for review of recent findings, see [36]). On the other hand, a slightly older neonate infected primarily during passage through a CMV infected uterine cervix rather than through the placenta can also become infected, but remains asymptomatic.

\section{Categories of diseases}

\section{CMV mononucleosis}

Klemola and Kaariainen [37] recognized a form of infectious mononucleosis in young adults caused by CMV on the basis of a rise in specific serology and a negative heterophile agglutinin test for EBV infection. The clinical syndrome is similar to EBV infectious mononucleosis. The patient had fever and atypical lymphocytes in the peripheral blood. Tonsillitis, pharyngitis and lymphadenopathy were less frequent than in EBV mononucleosis. It is interesting that this disease was first recognized in Finland, a well developed Northern European country, where the frequency of seropositivity is lower than in less developed countries, where most people are immune to CMV when they are adults.

Post transfusion CMV infection or disease is a special case of infection or mononucleosis transmitted by CMV in units of blood. Blood may contain leucocytes which may be the source of lytic infections, or demonstrable viremia. Infected cells were thought to be polymorphonuclear leucocytes and monocytes [38, 39]. But finding such cases of viremia in the normal adult population is extremely unusual. Despite repeated attempts, there is only one positive report in the literature [40]. It is more likely that viral transmission is effected by blood cells that contain latent, non-lytic virus which are then reactivated in the recipient.

Our studies in Pittsburgh may serve as an example of the nature of the problem of transmission by blood [41, 42]. We studied 93 seronegative children whose average age was 7.6 years. Thirteen percent seroconverted following open heart surgery after receiving an average of 3.9 units $(500 \mathrm{ml})$. Each unit of blood produced a $3.3 \%$ chance of conversion, or transmission of infection. As the seroprevalence rate in the general population in Pittsburgh is around $50 \%$, the risk of a unit of seropositive blood is $6.6 \%$. None of the children were ill. This degree of seroconversion, or infection, is consistent with 18 other studies in normal subjects [40].

This calculated risk and danger however underestimates the frequency of latently infected blood from donors. Yeager et al. [43] found that this is a function of the nature of recipients. She showed different risks in transfusions of neonates, many of whom were immature babies. When neonates whose mothers were seronegative were given blood from seropositive donors, 10 out of 74 (13.5\%) became primarily infected, demonstrated by viruria in the recipient. Five infants died or were seriously ill $(6.8 \%)$. When 90 neonates, whose mothers were seronegative were given blood from seronegative donors, none became infected and none died. This result suggested to her a new policy of prevention of CMV in neonates born of seronegative mothers by giving them only blood from seronegative donors. The infecting dose of blood was calculated to be between 50 and $100 \mathrm{ml}$.

A similar situation occurs in adults who undergo bone marrow transplantation. This procedure involves essentially destruction of host defenses before successful engraftment of the marrow transplant, at which time the patient is at high risk for serious and fatal CMV disease, especially pneumonia. One possible source of the virus is seropositive blood and blood products. Bowden et al. [44] tested the effect of providing only seronegative blood and blood products for transplant recipients who were seronegative. In 32 patients who were treated in this manner, there was one infection, while in 25 seronegative control patients who received standard blood products, there were 8 (3.1 vs $32 \%$, $P<0.007)$. Using only seronegative blood and blood products in seronegative marrow recipients became the standard practice at the University of Washington.

\section{Congenital CMV infection (CID)}

About 1\% (40,000 a year) of babies born in the United States are congenitally infected. Of these about $5 \%$ are symptomatic at birth. They may be small for their gestational age, and have petechiae, jaundice, hepatosplenomegaly, thrombocytopenia, chorioretinitis, microcephaly or hearing loss. Hearing loss may be identified only later in life [45]. The presence of periventricular calcification seen on CT scan is a typical finding in severe cases. Most of these cases are from primary infections in the mother, but congenital CMV infection has now been identified in mothers who were immune before their pregnancies. Some have developed neurosensory hearing loss [17]. 


\section{CMV diseases in AIDS}

Except for CID in infants, the most severe cases of CMV diseases have been found in patients with AIDS. Uncharacteristically, they have occurred, at least in adults, in seropositive or previously immune subjects. Another unusual characteristic of CMV disease in AIDS is the severe involvement of the central nervous system. This suggests that probably most body parts are potentially permissive for cytomegalovirus infection. This again reflects on the ubiquity of latent CMV infection. There is a gradient of organs and cells that become involved in disease which is a function of the severity of immunological deficiency.

CMV disease occurred in $21-44 \%$ of AIDS patients before the introduction of highly active antiretroviral therapy (HAART), usually late in their disease when the CD4 lymphocyte count was below $50 \mu \mathrm{L}$ [46]. CMV retinitis is the most disabling and characteristic disease, as it involves loss of sight. Antiviral therapy has been most effective in this area (see "therapy", below). Reversal of immunological deficiency and rise of CD4 counts toward normality has been an effective preventive against CMV retinitis [47].

CMV polyradiculopathy is the most frequent and characteristic involvement of the central nervous system. Patients experience weakness, loss of reflexes and sensation, usually in the legs, and loss of control bladder and anal function. The cerebrospinal fluid shows evidence of infection, pleocytosis and low sugar levels [48]. CMV mononeuritis is less common.

There are two types of CMV encephalitis. The first type is difficult to distinguish from HIV dementia. It is a diffuse, multifocal, micronodular encephalitis [49]. Both types exhibit cognitive and motor disturbances such as forgetfulness, confusion, impaired memory and unsteadiness. CMV cannot be cultured in the CSF, but CMV PCR is almost always positive. The second is a ventriculoencephalitis reminiscent of what is observed in neonatal CID [49]. Ventriculitis can be demonstrated by magnetic resonance imaging with gadolinium enhancement [50]. Patients have acute onset of apathy, disorientation, cranial nerve palsies, abnormal CSF and a rapid downhill course. Ganciclovir treatment may be partly responsive [51].

The gastrointestinal tract from the mouth, esophagus, stomach, small intestines, colon to the rectum may be involved in both AIDS and after transplantation. There may be painful erosions of the mouth, epiglottis or pharynx. Painful ulcerations of the esophagus associated with dysphagia, odynophagia and upper gastrointestinal bleeding occur. Stomach ulcers may cause bleeding, obstruction or perforation. Studies indicate $30-90 \%$ of AIDS patients develop chronic diarrhea and wasting [52]. In Africa, there is a syndrome called "slim disease". Often it is not possible to determine which virus, bacterium, parasites or fungus may be responsible.

\section{CMV diseases after allograft transplantation}

CMV is the single most important cause of infectious diseases after organ transplantation. It affects $75 \%$ of the organ recipients during one year after transplantation [53]. In a prospective study, Ho et al. [32] found that $80 \%$ of seronegative recipients converted to seropositivity after they received a kidney from a seropositive donor. Summarizing 16 studies of kidney transplantations, Ho [54] calculated that $52 \%$ of pretransplant seronegative recipients became primarily infected after transplantation and converted to seropositivity. Since not all donors of kidneys were seropositive, one can surmise that practically all seropositive donors had latent CMV infections that were reactivated in the recipient. Similar figures were obtained after cardiac, liver and marrow transplantations. This is evidence that probably all organs in seropositive subjects have latent CMV infection [55].

The morbidity of CMV infection was different in primary compared to secondary infections after kidney transplantation. Primary infections were $83 \%$ symptomatic; that is they at least had fever. Some had pneumonias. Secondary infections were $44 \%$ symptomatic, being usually limited to mononucleosis type of symptomology [55, 56].

Morbidity also varied depending on the type of transplantation. The most severe type of pathology was pneumonia in bone marrow transplantation, with a mortality of $84 \%$ [57]. This type of pneumonia was probably complicated by additional immunopathology unrelated to CMV, a graft versus host reaction. Pneumonia in kidney transplantation had a mortality of $48 \%$ [58]. The frequencies of CMV pneumonia after different transplantations decreased in the following order: heart-lung $>$ heart>liver $>$ kidney (32, 8,3 and $2 \%$ ) [59, 60]. The reason why pneumonias should occur so frequently after heart-lung and heart transplantations is obscure. In the beginning it was thought that the reason lay in the type or dose of immunosuppressants used. Indeed, before their use was moderated, it was found that antilymphocyte serums or OKT-3 serum enhanced the severity of post-transplant CMV disease [61, 62]. However when a new immunosuppressive agent was introduced in renal transplantation, such as cyclosporine or tacrolimus [63, 64], CMV disease was not enhanced. In fact all four types of transplantations cited above were performed at the University of Pittsburgh where similar prednisone-cyclosporine immunosuppressant regimes without antilymphocyte serum were used. Heart and heart-lung transplantations must have some unknown general or local immnosuppressive effect apart from the drugs used. Indeed, CMV pneumonia is such a problem after heart transplantations that 
additional preventive and therapeutic measures are now routinely practiced (see below).

\section{Antiviral therapy and prevention of CMV diseases}

There are now effective drugs against lytic CMV infections [65]. Therapy does not affect the latent virus. In that respect, there is no cure for CMV disease as infection will persist in the latent state.

Ganciclovir \{[9-(1,3-dihydroxy-2-propoxy)methyl]-guanine, DHPG $\}$ is an acyclovir nucleoside synthesized in 1982. It is a potent inhibitor of the reproduction of herpesviridae [66]. It has been the drug of choice against CMV for the last twenty-five years. It is usually given intravenously. An oral preparation is available in the form of the monovalyl ester of ganciclovir (valganciclovir, [65]).

If ganciclovir cannot be tolerated, or if resistance develops against it, foscarnet and cidofovir are available as intravenous drugs. Formivirsen is an FDA approved antisense compound to be used intravitreously against CMV retinitis when other agents cannot be used [65].

One of the most gratifying experiences in antiviral therapy was to observe the efficacy of ganciclovir against CMV retinitis in AIDS [67-69]. Sight was saved and the progression of the retinal lesions stopped! However it was found that when therapy was discontinued, the disease would recur. Further treatment was usually necessary, especially in the pre HAART days when no improvement of immunity could be anticipated. Prolonged use of ganciclovir often resulted in leucopenia and other hematological side effects. Other drugs had to be used. Intravitreal injections was one way to avoid toxicity of the systemic drugs. With the inception of HAART, when the CD4 count could be brought above 100 cells per $\mu \mathrm{L}$, it was finally possible to stop antiviral drugs [47].

Ganciclovir has been used to treat other CMV diseases in AIDS and after organ transplantation in the lung, the gastrointestinal tract, and the central nervous system. Its effectiveness is related to the degree of immunodeficiency associated with the disease in question. It can vary from stabilizing the disease during therapy but without objective improvement to complete clearing of the pathology. It is least effective in treating diseases of the central nervous system, firstly, because involvement of that system does not occur unless immunity is severely deficient, as in the late stages of AIDS. Secondly, drugs may not be effective in the central nervous system because of the blood brain barrier prevents the achievement of an effective concentration of the antiviral drug [65].

There has been a great deal of research and study on the treatment and prevention of pneumonias, which is the most important disease after bone marrow and organ transplantations. Pneumonias after marrow transplantation have a mortality of 70-85\% [57]. Ganciclovir alone suppresses the virus but it does not reduce morbidity or mortality. Addition of immune globulin was found to reduce mortality to $30 \%$ [70]. This is now routine practice.

There are two methods of preventing CMV disease after major transplantations. The first is preemptive treatment of patients with ganciclovir before onset of disease. For the first few months after transplantation, patients undergo surveillance for signs of impending disease. This is indicated by three possible methods; CMV viremia, circulating CMV antigenemia or quantitative CMV PCR. In the antigenemia method CMV infection is diagnosed by the detection of CMV matrix protein pp65 in peripheral blood polymorphonuclear leukocytes. The quantity of antigen has been correlated with development of disease [71]. Qualitative and quantitative PCR assays for CMV DNA or RNA are available to diagnose or predict CMV disease in blood and in tissues [72]. The second method for preventing CMV disease is to administer ganciclovir to all patients for the period they are deemed to be at risk for disease, usually 90-100 days after transplantation [73, 74]. Both methods are effective, and are use especially in transplantations where the risk of CMV disease is high, that is after bone marrow, heart-lung, lung and heart transplantations.

\section{Summary and conclusions}

About one hundred years ago, developments in pathologic anatomy led to the recognition of the morphological cellular characteristics of infection by CMV. It took another 50 years before the virus was successfully cultured and isolated. The elucidation of its epidemiology, and its wide scope of infection followed when methods to measure intact virus and specific immunity became available.

The second half of the twentieth century was characterized by rapid advances in human technology and medicine as well as break down of social relationships that are important for the preservation of the family and individual health. These changes have had a profound effect on CMV infection and diseases. There are increasing numbers of individuals who are immunodeficient in general or specific ways and who are prone to CMV infection. The scope of CMV diseases has extended from a previously rare lethal, congenital infection to increasing numbers of patients who have undergone organ transplantation and who are immunosuppressed for the survival of their grafts. Break down of social relations contributed in the eighties to the emergence of a world wide pandemic of AIDS, a new disease of mankind that specifically destroys cellular immunity, the type of immunity responsible for holding latent CMV infection in check. CMV diseases are an integral part of clinical side of AIDS. 
The understanding of the molecular and chemical events of viral reproduction has made possible the development of effective antiviral compounds. They are able to arrest viral replication and restrict some of the pathologic processes of CMV diseases. They do not have long lasting effect, however, unless immunological competence can be restored.

The basis of persistence of CMV infection is latent infection. As long as CMV infection can revert to the latent state, it is incurable. Latent CMV lurks behind appearances and acts like fifth columnists which can activate into a lytic infection and subvert the host. Our understanding of latency, limited though it is, has not been dedicated technologically to its elimination.

We need new approaches to antiviral therapy targeted against latency. Along with basic understanding of the molecular biology [31], a parallel technological, pharmacological approach is needed. One is faced with the same type of challenge in this regard as in the development of a vaccine against CMV [18].

\section{References}

1. Ribbert H (1904) Ueber protozoenartige Zellen in der Niere eines syphilitischen Neugeborenen und in der Parotis von Kindern. Zbl All Pathol 15:945-948

2. Jesionek A, Kiolemenoglou B (1904) Ueber einen Befund von protozoenartigen Gebilden in den Organen eines hereditar-luetischen Foetus. Muenchner Med Wochenschr 51:1905-1907

3. Lòwenstein C (1907) Ueber protozoenartige Gebilde in den Organen von Kindern. Zbl Allg Pathol 18:513-718

4. Von Glahn WC, Pappenheimer AM (1925) Intranuclear inclusions in visceral disease. Am J Pathol 1:445-465

5. Lipschuetz B (1921) Untersuchungen ueber die Aetiologie der Krankheiten der Herpes genitalis. Arch Dermatol Syph 136:428482

6. Farber S, Wolbach S (1932) Intranuclear and cytoplasmic inclusions (protozoan-like bodies) in the salivary glands and other organs of children. Am J Pathol 8:123-135

7. Wyatt JP, Saxton J, Lee RS, Pinkerton H (1950) Generalized cytomegalic inclusion disease. J Pediatr 36:271-294

8. Fetterman GH (1952) A new laboratory aid in the diagnosis of inclusion disease of infancy. Clin Pathol 22:424-425

9. Minder WH (1953) Die Aetiologie der Cytomegalia infantum. Schweiz Med Wochenschr 83:1180-1182

10. Enders JF, Weller TH, Robbins FC (1949) Cultivation of the lansing strain of poliomyelitis virus in cultures of various human embryonic tissues. Science 109:85-87

11. Weller TH, Macauley JC, Craig JM, Wirth P (1957) Isolation of intranuclear inclusion producing agents from infants with illnesses resembling cytomegalic inclusion disease. Proc Soc Exp Biol Med 94:4-12

12. Smith MG (1956) Propagation in tissue cultures of a cytopathogenic virus from human salivary gland virus (SVG) disease. Proc Soc Exp Biol Med 92:424-430

13. Rowe WP, Hartley JW, Waterman S et al (1956) Cytopathogenic agent resembling human salivary gland virus recovered from tissue cultures of human adenoids. Pro Soc Exp Biol Med 92:418-424
14. Weller TH (1953) Serial propagation in vitro of agents producing inclusion bodies derived from varicella and herpes zoster. Proc Soc Exp Biol Med 83:340-346

15. Weller TH (1970) Cytomegalovirus: the difficult years. J Infect Dis 122:532-539

16. Weller TH, Hanshaw JB, Scott DE (1960) Serologic differentiation of viruses responsible for cytomegalic inclusion disease. Virology 108:843-868

17. Boppana SB, Rivera LB, Fowler KB et al (2001) Intrauterine transmission of cytomegalovirus to infants of women with preconceptional immunity. N Engl J Med 344:1366-1371

18. Arvin AM, Fast P, Myers M, Plotkin S, Rabinovich R (2004) Vaccine development to prevent cytomegalovirus disease: report from the National Vaccine Advisory Committee. Clin Infect Dis 39:233-239

19. Cha TA, Tom E, Kemble GW et al (1996) Human cytomegalovirus clinical isolates carry at least 19 genes not found in laboratory strains. J Virol 70:78-83

20. Krech U, Jung M, Jung F (1971) CMV infections in man. S. Karger, Basel, 124 pp

21. Reynolds DW, Stagno S, Hosty TS et al (1973) Maternal cytomegalovirus excretion and perinatal infection. N Engl J Med 289:1-5

22. Stagno S, Reynolds DW, Pass RF, Alford CA Jr (1980) Breast milk and the risk of cytomegalovirus infection. N Engl J Med 302:1073-1074

23. Numazaki Y, Yano N, Morizuka T et al (1970) Primary infection with human cytomegalovirus: virus isolation from healthy infants and pregnant women. Am J Epidemiol 91:410-417

24. Lamb SB, Stern H (1966) Cytomegalovirus mononucleosis with jaundice as presenting sign. Lancet 2:1003-1007

25. Chretien JH, McGinnis CG, Muller A (1977) Venereal causes of cytomegalovirus mononucleosis. JAMA 238:1644-1645

26. Handsfield HH, Chandler SH, Caine VA et al (1985) Cytomegalovirus infection in sex partners: evidence of transmission. J Infect Dis 151:344-348

27. Drew WL, Sweet ES, Miner RC et al (1984) Multiple infections by cytomegalovirus in patients with acquired immune deficiency syndrome: documentation by southern blot hybridization. J infect Dis 155:891-896

28. Coutinho RA, Van Dillen PW, Van Lent PA et al (1984) Infection with cytomegalovirus in homosexual men. Br J Vener Dis 60:249252

29. Collier AC, Meyers JD, Corey L et al (1987) Cytomegalovirus infection in homosexual men. Am J Med 82:593-600

30. Mintz L, Drew WL, Miner RC, Braff EH et al (1983) Cytomegalovirus infections in homosexual men. Ann Intern Med 99:326-329

31. Reddehase MJ (2006) Cytomegaloviruses: molecular biology and immunology, Caister Academic Press, Norfolk, 619 pp

32. Ho M, Suwansirikul S, Dowling JN et al (1975) The transplanted kidney as a source of cytomegalovirus infection. New Engl J Med 293:1109-1112

33. Ho M (1991) Cytomegalovirus: biology and infection, 2nd edn, Chap 13. Plenum, New York, pp 249-300

34. Hendrix RM, Wagenaar M, Slobbe RL, Bruggeman CA (1997) Widespread presence of cytomegalovirus DNA in tissues of healthy trauma victims. J Clin Pathol 50:59-63

35. Sinclair J, Sissons P (1996) Latent and persistent infections of monocytes and macrophages. Intervirology 39:293-301

36. Pereira L, Maidji E, McDonagh S, Tabata T (2006) Routes of human CMV transmission and infection at the uterine-placental interface. In: Reddehase MJ (ed) Cytomegaloviruses: molecular biology and immunology, Chap 3. Caister Academic Press, Norfolk, pp 29-48

37. Klemola E, Kaariainen L (1965) Cytomegalovirus as a possible cause of a disease resembling infectious mononucleosis. Br Med J 2:1099-1102 
38. Rinaldo CR, Levin MJ, Carney WP et al (1979) Interaction of lymphocytes with cytomegalovirus. In: Proffit MR (ed) Virus-lymphocyte interactions: implications for disease. Elsevier-North Holland, Amsterdam, pp 267-282

39. Saltzman RL, Quirk MR, Jordan MC (1988) Disseminated cytomegalovirus infecton. Molecular ananlysis of virus and leukocyte interactions in viremia. J Clin Invest 81:75-81

40. Diosi P, Moldovan E, Tomescu N (1969) Latent cytomegalovirus infection in blood donors. Br Med J 4:660-662

41. Armstrong JA, Tarr GC, Ho M et al (1976) Cytomegalovirus infection with in children undergoing open-heart surgery. Yale $\mathrm{J}$ Biol Med 49:83-91

42. Ho M (1991) Cytomegalovirus: biology and infection, 2nd edn. Plenum, New York, p 177, 440 pp

43. Yeager AS, Grumet FC, Hafleigh EB et al (1981) Prevention of transfusion-acquired cytomegalovirus infections in newborn infants. J Pediatr 98:281-287

44. Bowden RA, Sayers M, Flournoy N et al (1986) Cytomegalovirus immune globulin and seronegative blood products to prevent primary cytomegalovirus infection after marrow transplantation. $\mathrm{N}$ Engl J Med 314:1006-1010

45. Demmler GJ (1991) Summary of a workshop on surveillance for congenital cytomegalovirus disease. Rev Infect Dis 13:315-329

46. Gallant JE, Moore RD, Richman DD et al (1992) Incidence and natural history of cytomegalovirus disease in patients with advanced human immunodeficiency virus disease treated with zidovudine. J Infect Dis 166:1223-1227

47. Verbraak FD, Boom R, Wertheim-van Dillen PM et al (1999) Influence of highly active antiretroviral therapy (HAART) on the development of CMV disease in HIV positive patients at high risk for CMV disease. Br J Ophthalmol 83:1186-1189

48. Cohen BA, McArthur JC, Grohman S et al (1993) Neurologic prognosis of cytomegalovirus polyradiculomyelopathy in AIDS. Neurology 43:493-499

49. Holland NR, Power C, Mathews VP et al (1994) Cytomegalovirus encephalitis in acquired immunodeficiency syndrome (AIDS). Neurology 44:507-514

50. Haymaker W, Girdany BR, Stephens J et al (1954) Cerebral involvement with advanced periventricular calcification in generalized cytomegalic inclusion disease in the newborn. J Neuropathol Exp Neurol 13:562-586

51. Price TA, Digioia RA, Simon GL (1992) Ganciclovir treatment of cytomegalovirus ventriculitis in a patient infected with human immunodeficiency virus. Clin Infect Dis 15:606-608

52. Bartlett JG, Laughon B, Quinn TC (1988) Gastrointestinal complications of AIDS. In: DeVita VT, Hellman S, Rosenberg SA (eds) AIDS, etiology, diagnosis, treatment and prevention, 2nd edn. Lippincott, Philadelphia, pp 227-244

53. Pereyra F, Rubin RH (2004) Prevention and treatment of cytomegalovirus infection in solid organ transplant recipients. Curr Opin Infect Dis 17:357-361

54. Ho M (1991) Cytomegalovirus: biology and infection, 2nd edn. Plenum, New York, p 250, 440 pp

55. Ho M (1991) Cytomegalovirus: biology and infection, 2nd edn. Plenum, New York, p 251, 440 pp
56. Ho M (1991) Cytomegalovirus: biology and infection, 2nd edn. Plenum, New York, p 257, 440 pp

57. Meyers JD, Flournoy N, Thomas ED (1986) Risk factors for cytomegalovirus infection after human marrow transplant. J Infect Dis 153:478-488

58. Peterson PK, Balfour HH, Marker SC et al (1980) Cytomegalovirus disease in renal allograft recipients: a prospective study of the clinical features, risk factors and impact on renal transplantation. Medicine 59:283-300

59. Ho M (1987) Infection and organ transplantation. In: Gelman S (ed) Anesthesia and organ transplantation. WB Saunders, Philadelphia, pp 49-60

60. Dummer JS, Montero CG, Griffith BP et al (1986) Infection in heart-lung transplant recipients. Transplantation 41:725-729

61. Rubin RH, Tolkoff-Rubin NE, Oliver D et al (1985) Multicenter seroepidemiologic study of the impact of cytomegalovirus infection on renal transplantation. Transplantation 40:243-249

62. Chou S, Norman DJ (1985) Effect of OKT3 antibody therapy on cytomegalovirus reactivation in renal transplant recipients. Transplantation Proc 17:2755-2756

63. Starzl TE, Fung J, Venkataramman R et al (1989) FK 506 for liver, kidney, and pancreas transplantation. Lancet 2:1000-1004

64. Thomason AW (1990) FK-506-how much potential? Immunol Today 11:6-9

65. Spector SA, Davis JL, Singh N (2006) Cytomegalovirus. http:// www.antimicrobe.org/12rev.asp

66. Cheng YC, Huang ES, Lin JC et al (1983) Unique spectrum of activity of 9-[(1,3-dihydro-2-propoxy)methyl]guanine against herpes simplex type 1. Proc Natl Acad USA 80:2767-2770

67. Felsenstein D, D'Amico DJ, Hirsch MS et al (1985) Treatment of cytomegalovirus retinitis with 9-[2-hydroxy-1-(hydroxymethyl) ethoxymethyl]guanine. Ann Intern Med 103:377-380

68. Felsenstein D, D'Amico DJ, Hirsch MS et al (1985) Treastment of cytomegalovirus retinitis with 9-[2-hydroxy-1-(hydroxymethyl) ethoxymethyl]guanine and high-dose corticosteroids. Ann Intern Med 105:214-215

69. Bach MC, Bagwell SP, Knapp NP et al (1985) 9-(1,3dihydroxy-2propoxymethyl)guanine for cytomegalovirus infections in patients with the acquired immunodeficiency syndrome. Ann Intern Med 103:381-384

70. Reed EC, Bowden RA, Dandliker PS et al (1988) Treatment of cytomegalovirus pneumonia with ganciclovir and intravenous cytomegalovirus immunoglobulin in patients with bone marrow transplants. Ann Intern Med 109:783-78

71. Lazzarotto T, Dal Monte P, Landini MP (1996) Recent advances in the diagnosis of cytomegalovirus infection. Ann Biol Clin $54: 259-265$

72. Spector SA, Merrill R, Wolf D et al (1992) Detection of human cytomegalovirus in plasma of AIDS patients during acute visceral disease by DNA amplification. J Clin Microbiol 30:2359-2365

73. Paya CV (2001) Prevention of cytomegalovirus disease in recipients of solid organ transplants. Clin Infect Dis 32:596-603

74. Singh N (2005) Late-onset cytomegalovirus disease as a significant complication in organ transplant recipients receiving antiviral prophylaxis: a call to heed mounting evidence. Clin Infect Dis 40:704-708 